\title{
Editorial
}

\section{Francisco de Paula Santander (1792-1840)}

La Academia Colombiana de Ciencias Exactas, Físicas y Naturales conmemora este año los 180 años del fallecimiento del General Francisco de Paula Santander, acaecido en Bogotá el 6 de mayo de 1840. La Academia busca, a través de sus acciones, mantener vivo el legado, la visión y el ideario del General Francisco de Paula Santander, considerando que tiene sus orígenes remotos en la Academia Nacional de Colombia y en la Academia Nacional de la Nueva Granada; así mismo, reafirma en su día a día la importancia de la educación y de la ciencia para el desarrollo del país, preceptos fundamentales de los gobiernos de Santander.

El recorrido del General Santander por las páginas de la historia de nuestra nación es simplemente sorprendente. Desde que adelantó estudios en el Colegio Mayor de San Bartolomé, institución educativa a la que ingresó el 17 de agosto de 1805 cuando tenía trece años de edad, hizo gala de sus dotes de liderazgo. En 1806, con catorce años, fue conciliario del Colegio, y en 1807 ya era secretario de la Junta Conciliar. En 1808 obtuvo el título de Bachiller que le fue otorgado por la Universidad de Santo Tomás, encargada de entregar estos títulos en esa época (Moreno de Ángel, 2019).

El 26 de octubre de 1810 ingresó al servicio militar, y ya con 18 años tuvo que enfrentar los rigores de la guerra. Su participación en la gesta libertadora lo llevó al oriente del país, donde tuvo acciones importantes que lo condujeron a reunirse con Simón Bolívar, quien le confió el cargo de Comandante del Ejército de Vanguardia.

José Asunción Suárez Niño (inéd.) describe con lujo de detalles la campaña que le permitió al General Santander lograr la primera y definitiva gran victoria del ejército patriota en el lugar conocido como Trincherón de Paya, o Termópilas de Paya, el 27 de junio de 1819, abriendo el camino para los triunfos posteriores en el Pantano de Vargas y el Puente de Boyacá. Para él, Santander era "gran conocedor de táctica, logística y estrategia, materias que puso en práctica como conductor de la victoria final”. Ocampo López (1992) se refiere a él como "el Organizador de la Victoria".

Santander abandonó su condición de militar y, ya como Vicepresidente de Cundinamarca designado durante el Congreso de Angostura el 17 de diciembre de 1819, se convirtió en "el hombre de las leyes", creando la institucionalidad tan necesaria para consolidar la nueva nación. Es entonces cuando, en una proclama del 2 de diciembre de 1921, expresa: "Las armas os han dado la independencia, las leyes os darán la libertad".

$\mathrm{Su}$ actividad política y de "arquitecto de la nación" constituyen una segunda etapa en la vida del General, en la que trabajó sin descanso administrando los recursos que permitieron la liberación de Venezuela, y organizando la hacienda pública, las relaciones exteriores y la educación pública (Ocampo López, 1992).

Son sus reformas educativas y su fuerte convicción de la importancia de la ciencia para “desarrollar la civilización intelectual, industrial y política", las que constituyen una tercera etapa en el recorrido del General por la historia del país, y lo convierten en el faro que inspira los objetivos y prioridades de la Academia Colombiana de Ciencias Exactas, Físicas y Naturales.

El General Santander, siendo un joven de 30 años, llevó a cabo la reforma educativa más importante y revolucionaria de su época, y una de las más sobresalientes en toda la historia de nuestro país. La reforma buscaba, entre otras cosas, que la enseñanza fuera más moderna, y que tuviera en cuenta los avances que se estaban dando en Europa. Según Santander: "sin un buen sistema de educación pública y enseñanza nacional, no puede difundirse la moral pública y todos los conocimientos útiles que hacen prosperar a los pueblos". "El triunfo sobre la ignorancia es muy brillante y glorioso y prepara la felicidad de los pueblos que cuando más ilustrados, conocen mejor sus derechos y se hacen más dignos de su libertad" (Ocampo López, 1992). 


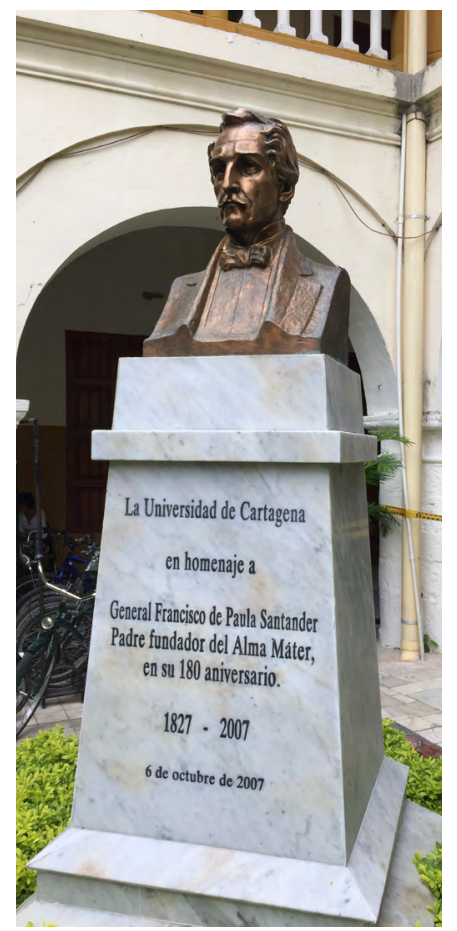

Figura 1. Monumento a Santander en el patio central de la Universidad de Cartagena.
Con gran visión, orientó la reforma al mejoramiento de la educación a todos los niveles, insistiendo, por ejemplo, en que la educación debería ser para todos los niños sin distinción de clases sociales. El plan incluía la decisión de "establecer una escuela en cada distrito o parroquia, y en cada cuerpo del ejército, una escuela de gramática en cada cabecera de Cantón, un colegio en cada provincia y una universidad en cada departamento" (Quintero Esquivel, 2017). Los departamentos eran, naturalmente, Caracas, Cundinamarca y Quito.

Para cumplirlo, en primer lugar concentró esfuerzos junto con José Manuel Restrepo, Secretario del Interior, en el establecimiento de colegios en prácticamente toda la república. Según información contenida en la obra Santander (Moreno de Ángel, 2019), ésta campaña educativa comenzó con la creación del Colegio de Boyacá, Tunja, el 17 de mayo de 1822, y se complementó así: Escuela Náutica de Cartagena, junio de 1822; Colegio de Antioquia en Medellín, 9 de octubre de 1822, que dio origen a la Universidad de Antioquia; Colegio San Simón en Ibagué, 21 de diciembre de 1822; Colegio Santa Librada en Cali, 29 de enero de 1823; Seminario o casa de educación en Pamplona, 6 de marzo de 1823; Casa de la Educación, Valencia, Venezuela, 15 de abril de 1823; Casa de la Educación, Trujillo, Venezuela, 3 de junio de 1823; Casa de la Educación, Tocuyó, Venezuela, 10 de septiembre de 1823; Colegio del Itsmo, Panamá, 6 de octubre de 1823; Casa de Estudios, Ocaña; 17 de mayo de 1824; Colegio San José en Guanentá en San Gil, 22 de mayo de 1824; Casa de la Educación, Vélez, 7 de julio de 1824; Colegio de Cumaná, Venezuela, 27 de octubre de 1824; Colegio de Cartagena, 8 de noviembre de 1824; Casa de la Educación, Guanare, Venezuela, 16 de mayo de 1825; Colegio del Socorro, 15 de enero de 1826; Colegio de Pasto, 2 de junio de 1827. También hay datos de la creación de colegios en Guayaquil (Colegio San Ignacio), Guayana, Mompós y Mérida. Adicionalmente creó el Colegio de la Merced en Bogotá, dedicado a la educación básica femenina (Díaz-Piedrahita, 2012).

La reforma educativa se extendió al nivel universitario. En 1820 divulgó un plan transitorio para el Estado de Cundinamarca, que respetaba en buena medida la tradición educativa basada en la filosofía escolástica, y era bastante conciliador con las autoridades eclesiásticas.

El Nuevo Plan de Estudios, promulgado en 1826, dio origen a una fuerte polémica, principalmente por el hecho de que instituía el Tratado de legislación civil y penal de Jeremías Bentham, como obra de estudio obligatorio en las facultades de Jurisprudencia. El "utilitarismo" de Bentham era considerado como una "doctrina perniciosa para la formación de la juventud". Quintero Esquivel (2017) incluyó en su artículo sobre "El proyecto ilustrado de Santander y la fundación de la Universidad del Cauca" tanto el contenido del plan transitorio de 1820 como el del nuevo plan de 1826 .

Fue 1826 el año de creación de la Universidad Central con sedes en Caracas, Bogotá y Quito (Ley del 28 de marzo de 1826 y Decreto del 3 de octubre del mismo año). La sede de Bogotá fue inaugurada el 25 de diciembre. La Universidad de Santo Tomás, de los Padres Dominicos, fue suspendida y remplazada por la Universidad Central de Bogotá, lo cual originó un serio conflicto. Además, la mayor parte de las cátedras que se dictaban en los colegios de San Bartolomé y el Rosario se trasladó a la Universidad Central, que pasó a depender del Estado, convirtiéndose en la primera universidad pública del país. Personajes tan prestantes de la vida colombiana como los doctores José Félix Patiño y Fernando Sánchez Torres, médicos y exrectores de la Universidad Nacional de Colombia, entre muchos otros, consideran a la Universidad Central como el origen de la actual Universidad Nacional de Colombia, y a Santander y sus colaboradores como sus verdaderos precursores.

El 24 de abril de 1827 se crearon las universidades de Popayán y Cartagena (Figura 1).

Lamentablemente, la oposición de los enemigos de Santander, y de la iglesia, sumados al atentado del 25 de septiembre de 1828, llevaron a Bolívar a cancelar la estructura liberal que le había dado Santander a la educación, y retroceder a la estructura colonial, a través de una circular con fecha 20 de octubre de 1828, y de un decreto que devolvió los colegios de San Bartolomé y el Rosario al estado que tenían en octubre de 1826, y se derogaron todas las disposiciones de la ley del 18 de marzo y el decreto del 3 de octubre de 1826. (Moreno de Ángel, 2019). 
Además de su interés por la educación, Santander procuró retomar el trabajo de la Expedición Botánica de José Celestino Mutis, convencido como estaba de la necesidad de conocer el territorio nacional desde diversas perspectivas. Pare ello, creó en 1823 la Misión Científica Permanente, también conocida como Misión Zea, ya que puso al frente de esa empresa a Don Francisco Antonio Zea. El objeto era traer de Europa a un grupo de científicos para que estudiaran nuestros recursos naturales.

Por otra parte, su interés en la ciencia como motor de desarrollo lo llevó a crear, en su condición de Vicepresidente, la Academia Nacional de Colombia según la Ley del 18 de marzo de 1826. Habiendo sido elegido Presidente en 1832, estableció la Academia Nacional de la Nueva Granada a través del Decreto Ejecutivo de 15 de noviembre de 1832, basado en la Ley del 18 de marzo de 1826. La instalación de esta nueva Academia tuvo lugar el 6 de enero de 1833 en el Palacio de Gobierno. bajo la presidencia de Santander.

La Academia Colombiana de Ciencias Exactas, Físicas y Naturales tiene pues sus orígenes remotos en las dos Academias creadas por el General Santander. Mi condición de Presidente de la Academia en el momento de conmemorar los 180 años de su fallecimiento me llena de orgullo, pues guardo por él un profundo sentimiento de admiración que me acompaña desde mi juventud. Nunca imaginé que un día podría expresar estas sensaciones en un momento tan especial.

La Academia honra en diversas formas la memoria de quien ha sido reconocido por los historiadores como "el organizador de la victoria", "el hombre de las leyes", "el arquitecto de la nación" y "el fundador de la educación pública en Colombia". A todas estas distinciones se puede agregar sin lugar a duda la de "el primer impulsor de la ciencia como motor de desarrollo".

Por esto, la Academia estableció en el año 2018 la condecoración Medalla General Francisco de Paula Santander, que ha sido entregada a personas que de una forma u otra han mantenido vivo su legado. Adicionalmente, para cumplir un compromiso con la Vicepresidencia de la República dentro de los actos del bicentenario de la independencia nacional, se realizó una sesión especial en la Academia el día 27 de junio de 2019, cuando se celebraban 200 años de la batalla del Trincherón de Paya. Ese mismo jueves 27 de junio de 2019 tuvo lugar el acto más significativo en la historia reciente de la Academia en relación con el General, al entronizar su imagen en el recinto de la institución (Figura 2).

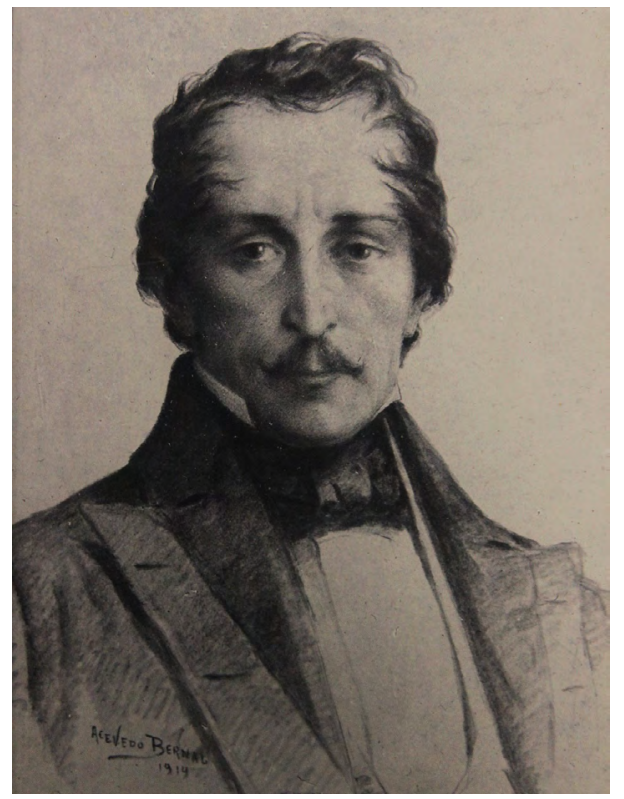

Figura 2. Francisco de Paula Santander - 1914. Ricardo Acevedo Bernal (Bogotá, 1867 - Civitavecchia, Italia; 1930). 
La Junta Directiva, en una de sus reuniones de 2019, resolvió por iniciativa del Académico Horacio Torres, que el año 2020 fuera el "Año Santander". Y se acordó en diversas instancias tales como la Junta misma y el Grupo de Historia y Filosofía de Ciencia, que habría varias actividades en las que se recordaría a Santander al cumplirse 180 años de su fallecimiento. Estas incluían ciclos de conferencias, un número de la revista y la Sesión Solemne Estatutaria del mes de agosto dedicada a su memoria. Aunque por diversas razones fue preciso desistir de los ciclos de conferencias, se había pensado realizar algunas actividades en los Capítulos de la Academia, lo cual se vio frustrado por la emergencia sanitaria. La sesión solemne estatutaria programada en homenaje a su vida, a su legado y, sobre todo, a su visión sobre la importancia de la educación y la ciencia para el futuro del país, efectivamente se realizó en forma virtual y con bastante éxito el miércoles 19 de agosto de 2020.

La Academia de los albores del Siglo XXI tiene como su objeto el desarrollo de las ciencias exactas, físicas y naturales, sus aplicaciones y su enseñanza. Para cumplirlo, la Academia fomenta y apoya la investigación científica, orienta a la sociedad en temas de interés nacional, contribuye a la divulgación y a la apropiación de la ciencia como elemento de cultura y desarrollo económico y social, y coopera en el mejoramiento de la enseñanza en los distintos niveles de la educación.

Tomando prestadas las palabras de la nota editorial del volumen 18, número 70 de la Revista de la Academia, escrita con ocasión de la celebración de los 200 años del nacimiento de Santander (2 de abril de 1792 - 2 de abril de 1992), la institución "sigue bajo los derroteros que le señalara su fundador, el General Francisco de Paula Santander, y que ratificaran sucesivamente quienes la han reorganizado y revitalizado a lo largo de 194 años, garantizando su vigencia”.

\section{Referencias}

Díaz-Piedrahita, S. (2012). Antecedentes de la Academia Colombiana de Ciencias Exactas, Físicas y Naturales. En: E. Forero González y S. Díaz Piedrahita (Eds.), La Academia Colombiana de Ciencias Exactas, Físicas y Naturales en los Albores del Siglo XXI. Bogotá: Acad. Colomb. Cienc. Ex. Fis. Nat. Edición Especial, pp. 14-44.

Moreno de Ángel, P. (2019). Santander. Bogotá: Planeta Colombiana S. A.

Ocampo López, J. (1992). Santander y la Academia Nacional. Rev. Acad. Colomb. Cienc. Ex. Fis. Nat. 18 (70): 383-388.

Quintero Esquivel, J. E. (2017). El proyecto ilustrado de Santander y la fundación de la Universidad del Cauca. Magazín Bicentenario. 1: 9-13. Popayán, Colombia: Publ. Universidad del Cauca.

Suárez Niño, J. A. (2019, inédito). Santander: Termópilas de Paya.

\section{Enrique Forero}

Presidente

Academia Colombiana de Ciencias Exactas, Físicas y Naturales

Agosto 2020 